\title{
ANALISA PENGARUH PENGENDALIAN KINERJA PROYEK TERHADAP MUTU PROYEK KONSTRUKSI DENGAN MENGGUNAKAN UJI STATISTIKA
}

\author{
Fatchur Rochman ${ }^{*}$, Hana Catur Wahyuni \\ Program Studi Teknik Industri, Fakultas Teknik, Universitas Diponegoro \\ Jl. Prof. Soedarto, SH, Kampus Undip Tembalang, Semarang, Indonesia 50275
}

(Received: August 30, 2016 / Accepted: February 28, 2017)

\begin{abstract}
Abstrak
Dalam proyek konstruksi perencanaan dan pengendalian merupakan fungsi yang paling pokok dalam mewujudkan keberhasilan suatu kegiatan di proyek konstruksi. Keberhasilan suatu proyek tidak lepas dengan serangkaian aktivitas yang meliputi tahapan perencanaan, pelaksanaan, dan pengawasan. Pengendalian, pengawasan serta pengukuran kinerja perlu dilakukan karena untuk mengetahui apakah dalam pelaksanaan pekerjaan terdapat penyimpangan dengan apa yang sudah ditetapkan. Maka dalam hal ini perlu dilakukan analisa untuk mengetahui indikator pengaruh pengendalian kinerja proyek (Keselamatan dan Kesehatan Kerja, Biaya, dan Waktu) terhadap Mutu proyek konstruksi menggunakan uji statistika.

Hasil penelitian menunjukkan secara simultan terdapat pengaruh positif dan signifikan antara variabel Keselamatan dan Kesehatan Kerja $\left(X_{1}\right)$, variabel Biaya $\left(X_{2}\right)$, dan variabel Waktu $\left(X_{3}\right)$ secara simultan terhadap Mutu $\left(Y_{1}\right)$ ditunjukkan nilai $F_{\text {hitung }}$ sebesar $(25.755)$ lebih besar dari $F_{\text {tabel }}(2.71)$ dengan tingkat signifikasi sebesar 0.000 yang lebih kecil dari sig. $(\alpha)$ sebesar 0.05.

Untuk secara parsial variabel Keselamatan dan Kesehatan Kerja $\left(X_{1}\right)$ menunjukkan nilai $t_{\text {hitung }}$ sebesar 3.672 dengan tingkat signifikasi sebesar 0.000 lebih besar dari $t_{\text {tabel }} 1.98667$ dan prosentase sebesar (37\%), variabel Biaya $\left(X_{2}\right)$ menunjukkan nilai thitung sebesar 1.705 dengan tingkat signifikasi sebesar 0.092 lebih kecil dari $t_{\text {tabel }} 1.98667$ dan prosentase sebesar $(17 \%)$, dan variabel Waktu $\left(X_{3}\right)$ menunjukkan nilai $t_{\text {hitung }}$ sebesar 1.705 dengan tingkat signifikasi sebesar 0.334 lebih kecil dari $t_{\text {tabel }}$ 1.98667 dan prosentase sebesar (17\%).
\end{abstract}

Kata Kunci: keselamatan dan kesehatan kerja; biaya; waktu; pengendalian kinerja; mutu proyek konstruksi

\begin{abstract}
In the construction project planning and controlling is the most basic function in realizing the success of an activity in construction project. A success a project cannot be separated by a series of activities which is included the stages of planning, implementation and controlling. Controlling, monitoring and performance measurement needs to be done as to determine whether there are deviation in the work implementation of what has been set. Then, in this case needs to be analyzed to know the effect of controlling project performance indicators (Occupational Safety and Health, Cost and Time) toward the quality of construction project.

The result of the research shows there is simultaneously a positive and significant influence between the variables of Occupational Safety and Health $\left(X_{1}\right)$, a Cost variable $\left(X_{2}\right)$ and a Time variable $\left(X_{3}\right)$ simultaneously toward Quality $\left(Y_{1}\right)$ is showed the value $F_{\text {count }}(25.755)$ is larger than $F_{\text {table }}(2.71)$ with significance level of 0.000 is smaller than sig. ( $\alpha$ ) of 0.05 .
\end{abstract}

\footnotetext{
${ }^{*}$ Penulis Korespondensi. email:
} 
For the partial variable of Occupational Safety and Health $\left(X_{1}\right)$ indicates $t_{\text {count }}$ amounted to 3.672 with significance level amount of 0.000 is larger than table 1.98667 and a percentage of (37\%), a cost variable $\left(X_{2}\right)$ indicates $t_{c o u n t}$ amounted to 1.705 with significance level amount of 0.092 is smaller than $t_{\text {table }} 1.98667$ and a percentage of $(17 \%)$, and a time variable $\left(X_{3}\right)$ is showed value of $t_{\text {count }}$ amounted to 1.705 with significance level amount of 0.334 is smaller than table 1.98667 and a percentage amount of $(17 \%)$.

Keywords: occupational safety and health; a cost; a time; controlling performance; quality of construction project

\section{Pendahuluan}

Kegiatan proyek merupakan suatu kegiatan yang bisa didefinisikan sebagai kegiatan yang tidak bisa berulang, dikerjakan pada jangka waktu tertentu untuk mendapat hasil sesuai dengan yang diharapkan. Menurut Junaidi (2012) pengendalian dalam proyek konstruksi pada umumnya menyangkut tiga aspek utama, yaitu, biaya, waktu, dan SDM.

Pembangunan proyek-proyek yang relatif besar dengan ketergantungan yang cukup kompleks, perencanaan dan pengendalian menjadi rumit. Pada hal ini pengontrolan dilakukan dengan terus agar benar-benar efisien dalam pengendaliannya. Dalam pelaksanaan suatu proyek konstruksi, perencanaan dan pengendalian merupakan fungsi yang paling pokok dalam mewujudkan keberhasilan suatu kegiatan di proyek konstruksi. Keberhasilan suatu proyek tidak lepas dengan serangkaian aktivitas yang meliputi tahapan perencanaan, pelaksanaan, dan pengawasan. Seperti yang dikemukakan Alan (2012) proses manajemen proyek adalah proses input; seperti penetapan tujuan, sasaran, informasi, data, dan sumber daya. Proses manajerial; meliputi perencanaan, pengorganisasian, pelaksanaan, dan pengendalian. Output; berupa luaran optimasi kinerja proyek, yaitu, biaya, waktu, safety (K3), dan mutu proyek.

Menurut Wibowo (2009) dalam Christina (2012) kinerja merupakan hasil pekerjaan yang mempunyai hubungan kuat dengan tujuan strategis organisasi, kepuasan konsumen, dan memberikan kontribusi ekonomis. Pengukuran kinerja perlu dilakukan karena untuk mengetahui apakah dalam pelaksanaan pekerjaan terdapat penyimpangan dengan apa yang sudah di tetapkan atau ditentukan ataukah kinerja dilakukan sesuai jadwal waktu yang ditentukan dan apakah kinerja sesuai dengan yang diharapkan.

Pada hal ini kenapa penelitian dilakukan, karena untuk mengetahui pengaruh pengendalian kinerja terhadap keberhasilan proyek konstruksi. Maka dari latar belakang diatas, penelitian ini mengarah kepada tujuan identifikasi dan melihat pengaruh apakah pengendalian kinerja proyek berhubungan dengan pencapaian mutu pada proyek konstruksi.

\section{Bahan Dan Metode Tahap Pengumpulan Data}

Pengambilan data dilakukan dengan proses wawancara pada pihak kontraktor dan staff (safety officer). Untuk penyebaran kuesioner dilakukan kepada semua karyawan baik staff, mandor, pekerja lapangan, serta pekerjaan yang berhubungan dengan pengendalian kinerja dan dengan tujuan melihat hubungan variabel Keselamatan dan Kesehatan Kerja, Biaya, dan Waktu dengan hasil akhir pada mutu proyek pada proses pengerjaan proyek pembangunan

Data yang digunakan dalam penelitian ini adalah data primer dan sekunder, sebagai berikut penjelasannya.

a. Data Primer yaitu data yang didapat dan diperoleh langsung dari orang-orang yang bersangkutan yaitu staff, mandor, pekerja lapangan. Pengambilan data dengan wawancara dan melalui penyebaran kuesioner.

b. Data Sekunder yaitu data yang didapat dengan cara mempelajari jurnal penelitian terdahulu, literatur, dan referensi dari perusahaan.

\section{Tahap Pengolahan Data}

Data yang diambil merupakan hasil penyebaran kuesioner yang telah disebarkan kepada karyawan dari top management sampai pekerja lapangan. Sebelum data diolah, data tersebut diuji keandalannya (valid) terlebih dahulu. Untuk melihat pengaruh pengendalian kinerja terhadap mutu proyek konstruksi, digunakan uji statistika dengan menggunakan SPSS 16.0.

Menurut Sugiyono (2004) dalam Janti (2014) instrumen dikatakan (valid) berarti menunjukkan alat ukur yang dipergunakan untuk mendapatkan data itu andal digunakan untuk mengukur apa yang seharusnya diukur. Data reliabel adalah data yang menunjukkan bahwa alat ukur yang digunakan dalam penelitian yang mempunyai keandalan sebagai alat ukur. Dengan kata lain, reliabilitas instrumen yang mencirikan tingkat konsistensi.

\section{Hasil Dan Pembahasan Uji Validitas dan Reliabilitas}

Pada Tabel 1. merupakan hasil dari pertanyaan yang diajukan kepada responden dan diolah menggunakan software SPSS 16.0 
Tabel 1. Hasil Uji Validitas

\begin{tabular}{|c|c|c|c|}
\hline $\begin{array}{c}\text { Varia } \\
\text { bel }\end{array}$ & Item & $\begin{array}{c}\text { Corrected Item } \\
\text { Total Correlation }\end{array}$ & Keterangan \\
\hline \multirow[t]{5}{*}{$\mathrm{X} 1$} & X1.1 & .645 & Valid \\
\hline & $\mathrm{X} 1.2$ & .500 & Valid \\
\hline & $\mathrm{X} 1.3$ & .446 & Valid \\
\hline & $\mathrm{X} 1.4$ & .461 & Valid \\
\hline & $\mathrm{X} 1.5$ & .337 & Valid \\
\hline \multirow[t]{5}{*}{$\mathrm{X} 2$} & $\mathrm{X} 2.1$ & .324 & Valid \\
\hline & $\mathrm{X} 2.2$ & .454 & Valid \\
\hline & $\mathrm{X} 2.3$ & .341 & Valid \\
\hline & $\mathrm{X} 2.4$ & .340 & Valid \\
\hline & $\mathrm{X} 2.5$ & .645 & Valid \\
\hline \multirow[t]{5}{*}{$\mathrm{X} 3$} & X3.1 & .501 & Valid \\
\hline & $\mathrm{X} 3.2$ & .534 & Valid \\
\hline & X3.3 & .645 & Valid \\
\hline & X3.4 & .645 & Valid \\
\hline & $\mathrm{X} 3.5$ & .500 & Valid \\
\hline \multirow[t]{5}{*}{ Y1 } & Y1.1 & .461 & Valid \\
\hline & Y1.2 & .302 & Valid \\
\hline & Y1.3 & .534 & Valid \\
\hline & Y1.4 & .459 & Valid \\
\hline & Y1.5 & .507 & Valid \\
\hline
\end{tabular}

Sumber: Hasil Analisa, 2016
Berdasarkan Tabel 1. bahwa pada kolom corrected item total correlation pada setiap item pertanyaan menunjukkan nilai korelasi $>0.3$ berarti pertanyaan tersebut valid.

Tabel 2. Hasil Uji Reliabilitas

\begin{tabular}{ccc}
\hline $\begin{array}{c}\text { Cronbach's } \\
\text { Alpha }\end{array}$ & N of Items & Keterangan \\
\hline .876 & 20 & Reliabel \\
\hline
\end{tabular}

Sumber: Hasil Analisa, 2016

Untuk melihat data itu reliabel dengan melihat Cronbach Alpha, nilai lebih dari $>0.6$ berarti data itu reliabel. (Trihendradi, 2011). Berdasarkan pada Tabel 2. diatas yaitu nilainya sebesar 0.876 . Hal ini dapat disimpulkan bahwa nilainya adalah reliabel dan dapat digunakan dalam penelitian selanjutnya.

\section{Uji Linieritas}

Untuk mengetahui apakah data tersebut linier atau tidak, dengan mengamati nilai signifikansi. Jika nilai signifikan dari Deviation from Linierity lebih besar dari 0.05 , ini mengindikasikan bahwa model regresi adalah linier.

Tabel 3. Hasil Uji Linieritas

\begin{tabular}{clcc}
\hline No & \multicolumn{1}{c}{ Variabel } & F & Sig. \\
\hline 1 & $\begin{array}{l}\text { Mutu* Keselamatan dan } \\
\text { Kesehatan Kerja }\end{array}$ & 2.195 & 0.062 \\
2 & Mutu* Biaya & 5.099 & 0.001 \\
3 & Mutu* Waktu & 0.961 & 0.446 \\
\hline
\end{tabular}

Sumber: Hasil Analisa, 2016

Berdasarkan Tabel 3. dijelaskan bahwa tingkat signifikan lebih besar (>) dari 0,05 maka model regresi memiliki hubungan yang linier. Untuk variabel Biaya tingkat signifikansinya 0.001 berarti model tidak memiliki hubungan linier, dan antara variabel Keselamatan dan Kesehatan Kerja dan variabel Waktu model tersebut linier terhadap Mutu Proyek.

\section{Uji Multikolenearitas}

Menurut Rahmadeni \& Anggreni (2014) untuk mendeteksi bahwa suatu model memiliki gejala multikolenieritas digunakan cara melihat VIF (Variance Inflatio Factor), dengan besar nilai VIF lebih kecil dari $10(<10)$, dan lebih besar dari 0.1 (> 0.1 ), maka diidentifikasi model persamaan regresi. Pada Tabel 4. Merupakan hasil pengolahan data. 
Tabel 4. Hasil Uji Multikolenearitas

\begin{tabular}{lcc}
\hline \multicolumn{1}{c}{ Variabel } & VIF & Keterangan \\
\hline Total K3 & 2.583 & Non Multikolinieritas \\
Total Biaya & 1.691 & Non Multikolinieritas \\
Total Waktu & 3.169 & Non Multikolinieritas \\
\hline
\end{tabular}

Berdasarkan Tabel 4. di atas bahwa hasil perhitungan VIF (Variance Inflatio Factor) lebih besar dari $(>0.1)$ dan lebih kecil dari $10(<10)$, maka dapat disimpulkan bahwa antara variabel yang satu dengan yang lain tidak saling berkolinearitas atau tidak ada korelasi antara variabel bebas.

Sumber: Hasil Analisa, 2016

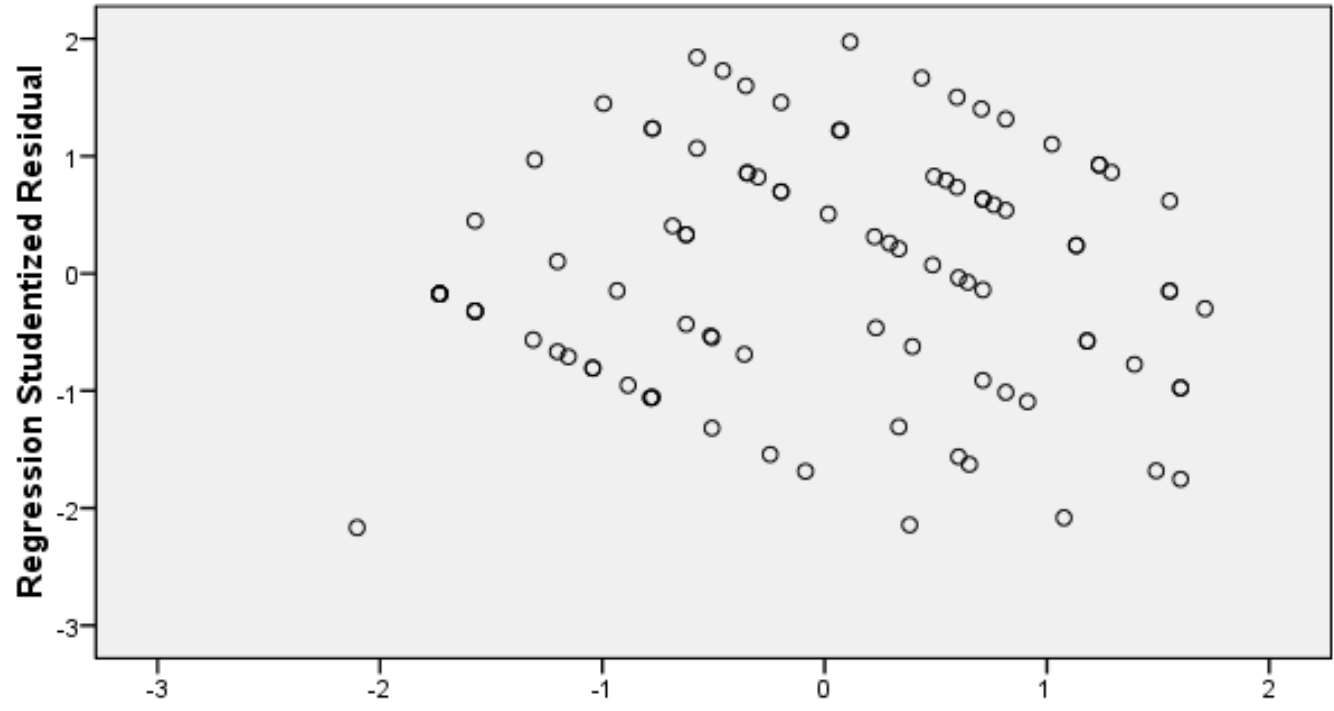

Gambar 1. Hasil Uji Heteroskedastisitas

Sumber: Hasil Analisa, 2016

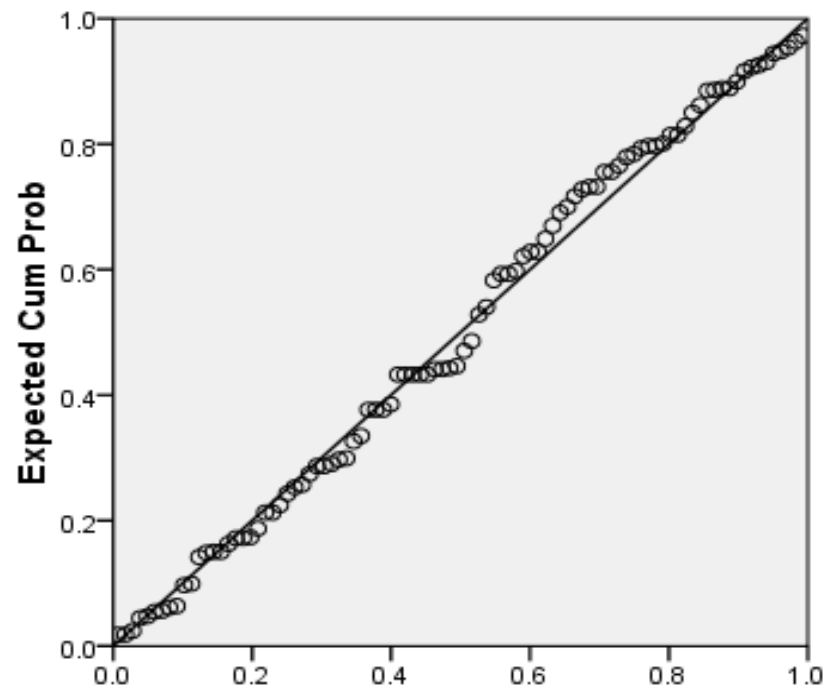

Gambar 2. Hasil Uji Normalitas

Sumber: Hasil Analisa, 2016 


\section{Uji Autokorelasi}

Digunakan untuk mengetahui korelasi antara residual pada suatu pengamatan dengan pengamatan lain dalam model regresi. Uji autokorelasi bisa dilakukan menggunakan uji Durbin-Watson (DW Test). Dari hasil perhitungan bahwa didapat nilai sebesar 1.807 maka tidak terjadi autokorelasi.

\section{Uji Heteroskedastisitas}

Untuk melihat apakah ada problem heteroskedastisitas atau tidak dengan melihat multivariate standardized scatterplot pada tabel pengujian. Serta melihat titik-titik penyebaran diatas dan di bawah angka 0 pada sumbu $\mathrm{Y}$ atau sumbu vertikal, Maka model regresi bersifat homogen atau tidak terjadi heteroskedastisitas. Pada Gambar 1. merupakan hasil uji heteroskedastisitas.

\section{Uji Normalitas}

Untuk mengetahui apakah variabel bebas dan variabel terikat berdistribusi normal atau sebaliknya. Data dikatakan terdistribusi normal apabila sebaran titik-titik mendekati garis diagonal. Pada gambar 2. merupakan hasil pengolahan data uji normalitas.

\section{Analisis Regresi Linier Berganda}

Digunakan untuk mengetahui pengaruh secara simultan maupun persial antara variabel independen (X) dan variabel dependen (Y).

Berdasarkan hasil yang diperoleh bahwa:

a. Nilai konstanta sebesar 2.739 menyatakan bahwa apabila tidak ada 3 variabel bebas, maka nilai variabel terikat sebesar 2.739 .

b. Nilai koefisien sebesar 0.508 menyatakan bahwa penambahan Keselamatan dan Kesehatan Kerja sebesar 1 akan meningkatkan Mutu.

c. Nilai koefisien sebesar 0.192 menyatakan bahwa penambahan Biaya sebesar 1 akan meningkatkan Mutu.

d. Nilai koefisien sebesar 0.137 menyatakan bahwa penambahan Waktu sebesar 1 akan meningkatkan Mutu.

\section{Analisis Korelasi}

Menurut Sugiyono (2007) pedoman untuk memberikan interpretasi koefisien korelasi sebagai berikut :

$$
\begin{array}{ll}
0.0-0.199 & =\text { sangat rendah } \\
0.20-0.399 & =\text { rendah } \\
0.40-0.599 & =\text { sedang } \\
0.60-0.799 & =\text { kuat } \\
0.80-1.000 & =\text { sangat kuat }
\end{array}
$$

Dari hasil diatas didapat korelasi antara variabel Keselamatan dan Kesehatan Kerja terhadap Biaya (r) adalah 0.303 sesuai dengan pedoman diatas maka bisa dikatakan hubungannya (rendah).
Dari hasil diatas didapat korelasi antara variabel Keselamatan dan Kesehatan Kerja terhadap Waktu (r) adalah 0.645 maka bisa dikatakan hubungannya (kuat). Maka dapat disimpulkan bahwa terjadi hubungan yang kuat antara variabel Keselamatan dan Kesehatan Kerja dan Biaya karena arah hubungan yang positif.

\section{Uji Hipotesis}

\section{Uji Simultan}

Berdasarkan hasil dari pengolahan data terdapat pengaruh secara simultan dari ketiga variabel Keselamatan dan Kesehatan Kerja, Biaya, dan Waktu. Hal ini bisa ditunjukkan dengan nilai sig. $0.000<0.05$ maka Ho ditolak dengan ketentuan bahwa $F_{\text {hitung }}>F_{\text {tabel }} 25.755>2.71$.Uji Parsial

a. Berdasarkan hasil dari pengolahan data didapat nilai probabilitas $0.000<0.361$ dengan prosentase sebesar (36\%), maka Ho ditolak. terdapat pengaruh signifikan variabel Keselamatan dan Kesehatan Kerja terhadap Mutu dengan ketentuan bahwa thitung $>\mathrm{t}_{\text {tabel }}$, $3.672>1.985$.

b. Berdasarkan hasil dari pengolahan data didapat nilai probabilitas $0.092>0.177$ dengan prosentase sebesar (17\%), maka Ho diterima. tidak terdapat pengaruh signifikan variabel Biaya terhadap Mutu dengan ketentuan bahwa $\mathrm{t}_{\text {hitung }}<\mathrm{t}_{\text {tabel }}, 1.705<1.985$.

c. Berdasarkan hasil dari pengolahan data didapat nilai probabilitas $0.334>0.102$ dengan prosentase sebesar (10\%), maka Ho diterima. tidak terdapat pengaruh signifikan variabel Waktu terhadap Mutu dengan ketentuan bahwa $\mathrm{t}_{\text {hitung }}<\mathrm{t}_{\text {tabel }}, 0.971<1.985$.

\section{Kesimpulan}

Berdasarkan hasil penelitian yang sudah dilaksanakan dapat diambil kesimpulan sebagai berikut.

Pada pengujian simultan diperoleh kesimpulan bahwa terdapat pengaruh positif dan signifikan antara variabel Keselamatan dan Kesehatan Kerja $\left(\mathrm{X}_{1}\right)$, variabel Biaya $\left(\mathrm{X}_{2}\right)$, variabel Waktu $\left(\mathrm{X}_{3}\right)$ secara simultan terhadap Mutu $\left(\mathrm{Y}_{1}\right)$. Hal ini ditunjukkan dengan nilai Fhitung sebesar (25.755) lebih besar dari Ftabel (2.71) dengan tingkat signifikansi sebesar 0.000 yang lebih kecil dari sig. $(\alpha)$ sebesar 0.05 .

Pada pengujian persial diperoleh kesimpulan sebagai berikut.

a. Variabel Keselamatan dan Kesehatan Kerja $\left(\mathrm{X}_{1}\right)$ terdapat pengaruh signifikan secara parsial terhadap variabel Mutu $\left(\mathrm{Y}_{1}\right)$. Hal ini menunjukkan bahwa nilai thitung dalam penelitian ini adalah sebesar 3.672 dengan tingkat signifikasi sebesar 0.000 lebih besar dari ttabel 1.98667 dengan prosentase sebesar (37\%). 
b. Variabel Biaya $\left(\mathrm{X}_{2}\right)$ tidak terdapat pengaruh signifikan secara parsial terhadap variabel Mutu $\left(\mathrm{Y}_{1}\right)$. Hal ini menunjukkan bahwa nilai thitung dalam penelitian ini adalah sebesar 1.705 dengan tingkat signifikasi sebesar 0.092 lebih kecil dari ttabel 1.98667 dengan prosentase sebesar $(17 \%)$.

c. Variabel Waktu $\left(\mathrm{X}_{3}\right)$ tidak terdapat pengaruh signifikan secara parsial terhadap variabel Mutu ( $\left.\mathrm{Y}_{1}\right)$. Hal ini menunjukkan bahwa nilai thitung dalam penelitian ini adalah sebesar 1.705 dengan tingkat signifikasi sebesar 0.334 lebih kecil dari ttabel 1.98667 dengan prosentase sebesar (17\%)

Variabel Keselamatan dan Kesehatan Kerja $\left(\mathrm{X}_{1}\right)$ yang paling signifikan terhadap Mutu $\left(\mathrm{Y}_{1}\right)$. Dengan tingkat signifikasi sebesar 0.000 dan prosentase sebesar $(37 \%)$, koefisien determinasi parsial paling besar.

Pengendalian kinerja proyek merupakan hal yang tidak terlepas dari aktivitas pada proyek konstruksi. Pelaksanaan dan prosedur memegang peranan penting dalam meningkatkan kinerja proyek konstruksi, budaya seperti itu harus di mulai dari top management yang tinggi sehingga meningkatkan kinerja suatu proyek konstruksi.

\section{Daftar Pustaka}

Chritina, Y. W., Djakfar, L., Thoyib, A. (2012). “ $A$ Pengaruh Budaya Keselamatan dan Kesehatan Kerja (K3) Terhadap Kinerja Proyek Konstruksi" Vol. 6 No. 1, hal. 8395

D Orr, A. 2012. A Manajemen Proyek Lanjutan, PT Indeks, Jakarta Barat

Janti, S. 2014. “Analisis Validitas dan reliabilitas Dengan Skala Likert Terhadap Pengembangan SI/TI Dalam Penentuan Pengambilan Keputusan Penerapan Startegig Planning Pada Industri Garmen" ISSN: 1979 911X

Junaidi, H., Malingkas, G. Y., Walingitan, D. R. O. (2012). "Pengendalian Waktu dan Biaya Pada Tahap Pelaksanaan Proyek Dengan Menggunakan Metode Nilai Hasil” Vol. 1 No. 1, hal. 44-52

Rahmadeni \& Defi Anggreni. 2014. “Analisis Jmlah Tenaga Kerja Terhadap Jumlah Pasien RSUD Arifin Achmad Pekanbaru Menggunakan Metode Regresi Gulud" Vol. 12 No. 1 ISSN 2407-0939

Trihendradi, C. 2011. Langkah Mudah Melakukan Analisis Statistik Menggunakan SPSS 19. Yogyakarta: C.V Andi Offset

http://duwiconsultant.blogspot.co.id/2011/11/analisiskorelasi-parsial.html 